Ocean Engineering

January 2015, Volume 94 Pages 94-102

http://dx.doi.org/10.1016/j.oceaneng.2014.11.016

http://archimer.ifremer.fr/doc/00239/34990/

(c) 2014 Elsevier Ltd. All rights reserved.

\title{
An experimental/numerical study of the catch weight influence on trawl behavior
}

\author{
Priour Daniel ${ }^{1,{ }^{*}}$, De La Prada Amelia ${ }^{2}$ \\ ${ }^{1}$ Ifremer, BP 70, 29280 Plouzané, France \\ ${ }^{2}$ University of A Coruña, Laboratorio de Ingeniería Mecánica, 15403 Ferrol, Spain \\ * Corresponding author : Daniel Priour, email address : daniel.priour@ifremer.fr \\ amelia.delaprada@udc.es
}

\begin{abstract}
:
Measurements at sea during fishing trials on bottom trawl have revealed that the geometry of the trawl is affected by the catch. A series of 37 hauls of around $3 \mathrm{~h}$ were carried out during the French EFFICHALUT project. The aim of this project was to carry out improvements on the fishing gear in order to reduce energy consumption. For this project, numerous sensors were used: for bridle tension, door spread, vertical opening, and door attitude. The measurements show quite clearly that the door spread decreases and the bridle tension increases during most of the hauls. The door spread decreased by $1.35 \mathrm{~m} / \mathrm{h}$, with a standard deviation of $1.98 \mathrm{~m} / \mathrm{h}$ while the top bridle tension increased by $47 \mathrm{~kg} / \mathrm{h}$, with a standard deviation of $59 \mathrm{~kg} / \mathrm{h}$. The mean catch per haul was around $1.48 \mathrm{t}$. The modeling of the trawl gear and the catch with a FEM model helps to explain the variation in the door spread and the bridle tension: the numerical model shows a mean decrease of $1.06 \mathrm{~m} / \mathrm{h}$ for the door spread and a mean increase of $76.0 \mathrm{~kg} / \mathrm{h}$ for the top bridle tension. The modeling were developed by the first author in previous studies.
\end{abstract}

\section{Highlights}

Measurement at sea of a bottom trawl behavior. Measurements show that doors spread is affected by catch. Modeling of the bottom trawl with a FEM. Modeling of the catch in the trawl. The modeling fits pretty well with the measurements.

Keywords : Trawl, data, modeling, door spread, bridle tension, catch weight. 


\section{Introduction}

During the last couple of years, numerous studies on fuel efficiency of fishing gear have been carried out following the large increase in energy cost. One of them, the EFFICHALUT project (Priour, 2012), was dedicated to enhance the energy efficiency of the bottom trawl. During this project, numerous measurements at sea on the bottom trawl were carried out and exploited, but some findings have not been described because they were outside the scope of the project. In the present paper, we propose to analyze one of these findings, which is about the effect of catch on gear geometry behavior.

Trawl performance is investigated using flume tank tests (Ward and Ferro, 1993 and Ferro et al., 1996), full scale tests at sea (Sala et al., 2011), analytical modeling (Park, 2007), or numerical model (Lee et al., 2005, Tsukrov et al., 2003, Priour, 2003 and Priour, 2013a). These investigations take into account the design of the gear, the water speed, and the bottom contact, but there are few studies on catch effect in the bibliography; only two seem relevant. In the first study on this subject, which was based on exhaustive flume tank experiments, O'Neill et al. (2005) concluded that the towing speed and the maximum frontal area of the codend were the predominant components of the codend drag. The second study dealt with the development of a numerical-statistical model of the catch shape and volume inside the codend, also based on flume tank tests (Priour and Herrmann, 2005). 
However, these studies have their limitations (as mentioned in Priour \& Herrmann, 2005): i) they were based on scaled flume tank experiments; ii) the fish catch was reproduced as water bags, and it was not physically possible to reproduce the same ratio between the catch volume and the mean volume of a single fish used in the fishing process at sea; and iii) only the codend was tested in the flume tank, instead of the whole trawl.

Therefore, the aim of the present work is to analyze the effect of catch weight on trawl behavior by using the real measurements at sea from the EFFICHALUT project. Moreover, these measurements are compared with the solution obtained using a numerical model. It is worth noting that this study on catch effect, although less exhaustive, was presented previously by one of the authors in the DEMAT 2013 conference (Priour, 2013b).

The remainder of the paper is organized as follows: Section 3 describes the trawl and methodology followed for the experimental measurements. Section 4 describes the numerical model of the whole trawl, that is, the net, the wires, the doors, contact with the seabed, and the catch. Section 5 shows the results of the experimental measurements and the comparison with the numerical model. Finally, Sections 6 and 7 provide the Discussion and the Conclusions, respectively.

\section{Methodology for experimental measurements}

\subsection{Description of the trawl gear}

The trawl used in the experiments was a bottom trawl. The plans were provided by the fisherman and are shown in Figure 1. The doors, from the Morgere company (Oval Foil model), were $2.9 \times 1.85 \mathrm{~m}$ wide and weighed $1.4 \mathrm{t}$. The rigging is defined in Figure 2 . The warp length was around 3 times the water depth, $150 \mathrm{~m}$ for the first week at sea and $60 \mathrm{~m}$ for the second one. The main fish species were mackerel, whiting, gurnet, gurnard, horse mackerel, and sea bass. The fisherman operated the trawl at constant engine power $(1071 / \mathrm{h}$ of fuel).

\subsection{Measurements at sea}

Tests at sea were carried out for two weeks. The depth was around $50 \mathrm{~m}$ during the first week and $20 \mathrm{~m}$ for the second. The trawl was equipped with 6 tension sensors: on each bottom bridle, top bridle, and warp (Figure 3). The tension values were recorded using NKE SF sensors (range, 5 ton; accuracy, $25 \mathrm{~kg}$; and resolution, $2.2 \mathrm{~kg}$ ). The door depth, spread, and attitude (heel and trim) were also recorded. The sensors used were NKE S3AP for door attitude and SCANMAR sensor for the door spread. The water speed on the head rope and the ground speed, as well as the vertical opening of the mouth of the trawl, were measured. The water speed and the vertical opening were measured with SCANMAR sensors fastened to the headline of the trawl. The ground speed was measured with a GPS on the boat.

The duration of the haul was more than $1.5 \mathrm{~h}$; otherwise, the haul was removed from the set of hauls, such as the event at $677 \mathrm{~h}$ in Figure 4.

Not all the measurements were valid due to dysfunctioning sensors or loss of acoustic link between the acoustic sensors and the boat. A clean-up of the measurements was necessary: only the values for water speed between 1 and $8 \mathrm{~m} / \mathrm{s}$ were kept; otherwise, the loss of acoustic 
link with the sensor was suspected. For the same reason, the measurement of the door spread was kept if it was within the range defined by the mean values of the door spread of the haul plus or minus $15 \mathrm{~m}$. Similarly, the bridle tension (top and bottom) were kept if they were between 200 and $2000 \mathrm{~kg}$; otherwise, the measurements dit not seem reasonable.

Unfortunately, the catch of each haul was not recorded; only a rough evaluation of the total catch was made by the fisherman. The mean catch per haul was 1.48 tons.

\section{Modeling the gear}

\subsection{Finite element model}

The modeling is founded on the finite element method (FEM) model of the net based on a triangular element (Priour, 1999, 2013a). The FEM model takes into account the inner twine tension, the drag force on the net due to the current, the pressure created by the fish catch in the codend, the floatability and weight of the net, the contact on the bottom, and the contact between knots of the netting, which limits the closure of meshes.

The FEM model is able to describe all the net and cables; this means that for a trawl, the codend, the wings, the headline, and also the rigging up to the boat are taken into account.

The net is modeled into triangular elements, whereas the cables, warps, bridles, and bars are modeled in linear elements (bars).

Due to the high number of knots in structures made of netting, the time required for the determination of the equilibrium position of each knot is generally extremely long. Thus, thank to the FEM model, the triangular elements can cover a large number of meshes (Figure 3 ). The triangles are contiguous, which means that a vertex can belong to several triangles, and triangle boundaries are not necessarily parallel to the twines or to the diagonal meshes. Thus, the user is free to create the triangular elements. The refinement is easy: a triangular element can be divided into 3 triangles without any modification to the rest. Each vertex is linked to the net; thus, when the equilibrium position of each vertex is found, the equilibrium position of the net is also found.

In this FEM model, the diamond and square meshes, including the hexagonal ones, can be modeled. Diamond and square mesh netting has two twine directions ( $\mathbf{u}$ and $\mathbf{v}$ ), whereas the hexagonal mesh netting has three.

For diamond and square mesh netting ( 2 twine directions), each twine direction is kept parallel in each triangular element; in other words, all the $\mathbf{u}$ twines are kept parallel, like the $\mathbf{v}$ twines (Figure 5). This leads to a constant deformation for each twine direction in each triangular element; this means that all the $\mathbf{u}$ twines have the same deformation, like the $\mathbf{v}$ twines. Obviously, there is a variation in orientation and deformation from one triangular element to an adjacent one. This hypothesis is reasonable if the elements are small.

According to these hypotheses, the force on each vertex can be calculated. These forces depend on the position of the vertices. From these forces, the Newton-Raphson iterative method gives the equilibrium position of the net. 


\subsection{Twine tension}

Here, the forces due to twine tension are described for the diamond and square mesh netting as described in Priour 1999 and Priour 2013a. All the twines of a triangular element are modeled as a bar made of isotropic and elastic material. The material can have 2 elastic modulus - one in traction and one in compression (very low or zero) - to take into account the unstretched twine.

In each triangular element, the elongation of twines in the same direction is constant. Thus, mesh sides along the $\mathbf{u}$ twine have the same length $(|\mathbf{u}|)$, and all mesh sides along the $\mathbf{v}$ twine have the same length $(|\mathbf{v}|)$. The tension is $T_{u}(\mathrm{~N})$ along the $\mathbf{u}$ direction and $T_{v}$ along the $\mathbf{v}$ direction:

$$
\begin{aligned}
& T_{u}=E A \frac{|\mathbf{u}|-l_{0}}{l_{0}} \\
& T_{v}=E A \frac{|\mathbf{v}|-l_{0}}{l_{0}}
\end{aligned}
$$

where $E$ is the twine modulus of elasticity $(\mathrm{Pa}), A$ is the twine section $\left(\mathrm{m}^{2}\right), l_{0}$ is the unstretched length of the mesh side $(\mathrm{m})$, and $|\mathbf{u}|(|\mathbf{v}|)$ is the stretched length $(\mathrm{m})$ of the mesh side along the $\mathbf{u}(\mathbf{v})$ direction.

Further more, according to Figure 5, the triangular side vectors $\mathbf{S}_{12}\left(\mathbf{S}_{13}\right)$ are defined as the vectors from node 1 to node 2 ( 1 to 3 ):

$$
\begin{gathered}
\mathbf{S}_{12}=\left[\begin{array}{l}
x_{2}-x_{1} \\
y_{2}-y_{1} \\
z_{2}-z_{1}
\end{array}\right] \\
\mathbf{S}_{13}=\left[\begin{array}{l}
x_{3}-x_{1} \\
y_{3}-y_{1} \\
z_{3}-z_{1}
\end{array}\right]
\end{gathered}
$$

To calculate the tensions, the stretched length of the mesh sides must be calculated. As shown in Figure 5, the triangular side vectors $\mathbf{S}_{12}\left(\mathbf{S}_{13}\right)$ can also be expressed as follows:

$$
\begin{aligned}
& \mathbf{S}_{12}=\left(V_{2}-V_{1}\right) \mathbf{v}+\left(U_{2}-U_{1}\right) \mathbf{u} \\
& \mathbf{S}_{13}=\left(U_{3}-U_{1}\right) \mathbf{u}+\left(V_{3}-V_{1}\right) \mathbf{v}
\end{aligned}
$$

where $U_{1}, U_{2}, U_{3}, V_{1}, V_{2}$, and $V_{3}$ are the mesh number of the three vertices. From these two equations, the mesh side vector $\mathbf{u}$ and $\mathbf{v}$ can be deduced: 


$$
\begin{aligned}
& \mathbf{u}=\frac{V_{2}-V_{1}}{n} \mathbf{S}_{13}-\frac{V_{3}-V_{1}}{n} \mathbf{S}_{12} \\
& \mathbf{v}=\frac{U_{3}-U_{1}}{n} \mathbf{S}_{\mathbf{1 2}}-\frac{U_{2}-U_{1}}{n} \mathbf{S}_{\mathbf{1 3}}
\end{aligned}
$$

where $n$ is the number of mesh sides in the triangular element:

$$
n=\left(U_{3}-U_{1}\right)\left(V_{2}-V_{1}\right)-\left(U_{2}-U_{1}\right)\left(V_{3}-V_{1}\right)
$$

The forces on each vertex are calculated with the principle of virtual work. For example, $f_{x l}$ is the $\mathbf{X}$ component of the force on vertex 1 and assessed by a displacement $\left(d_{x l}\right)$ along $\mathbf{X}$ axis of the vertex 1 . This displacement leads to an external work for the triangular element:

$$
W_{e}=f_{x l} d_{x l}
$$

This displacement $\left(d_{x l}\right)$ induces a variation in twine length $(\mathrm{d}|\mathbf{u}| \& \mathrm{~d}|\mathbf{v}|)$ and, consequently, an internal work for the triangular element:

$$
W_{i}=\left(T_{u} d|\mathbf{u}|+T_{v} d|\mathbf{v}|\right) \frac{n}{2}
$$

Because of the principle of virtual work, the internal work must be equal to the external one, which gives

$$
f_{x l}=\left(T_{u} \frac{d|\mathbf{u}|}{d_{x l}}+T_{v} \frac{d|\mathbf{v}|}{d_{x l}}\right) \frac{n}{2}
$$

The derivatives of twine length can be deduced from Equations 5 and 6 . This gives the forces due to twine tension on the 3 vertices of the triangular element:

$$
\begin{aligned}
& \mathbf{F}_{1}=\left(V_{3}-V_{2}\right) T_{u} \frac{\mathbf{u}}{2|\mathbf{u}|}+\left(U_{2}-U_{3}\right) T_{v} \frac{\mathbf{v}}{2|\mathbf{v}|} \\
& \mathbf{F}_{2}=\left(V_{1}-V_{3}\right) T_{u} \frac{\mathbf{u}}{2|\mathbf{u}|}+\left(U_{3}-U_{1}\right) T_{v} \frac{\mathbf{v}}{2|\mathbf{v}|} \\
& \mathbf{F}_{3}=\left(V_{2}-V_{1}\right) T_{u} \frac{\mathbf{u}}{2|\mathbf{u}|}+\left(U_{1}-U_{2}\right) T_{v} \frac{\mathbf{v}}{2|\mathbf{v}|}
\end{aligned}
$$

\subsection{Hydrodynamic drag}

The drag force on the netting is calculated in this model as the sum of the drag force on each twine ( $\mathbf{u}$ and $\mathbf{v})$. This assumption leads to the calculation of the drag of each triangular element because each twine vector is known, as described earlier. The formulation of the drag is based on the assumptions of Morrison adapted by Landweber and Richtmeyer. The 
following equations are only presented for the $\mathbf{u}$ twines, but the expressions for $\mathbf{v}$ twines can be inferred similarly:

$$
\begin{aligned}
& \left|\mathbf{F}_{\mathbf{d}}\right|=\frac{1}{2} \rho C_{d} D l_{0}(|\mathbf{V}| \sin (\alpha))^{2} \frac{n}{2} \\
& \left|\mathbf{T}_{\mathbf{d}}\right|=\frac{1}{2} f \rho C_{d} D l_{0}(|\mathbf{V}| \cos (\alpha))^{2} \frac{n}{2} \\
& \frac{\mathbf{F}_{\mathbf{d}}}{\left|\mathbf{F}_{\mathbf{d}}\right|}=\frac{\mathbf{u} \wedge(\mathbf{V} \wedge \mathbf{u})}{|\mathbf{u} \wedge(\mathbf{V} \wedge \mathbf{u})|} \\
& \frac{\mathbf{T}_{\mathbf{d}}}{\left|\mathbf{T}_{\mathbf{d}}\right|}=\frac{\mathbf{F}_{\mathbf{d}} \wedge\left(\mathbf{V} \wedge \mathbf{F}_{\mathbf{d}}\right)}{\left|\mathbf{F}_{\mathbf{d}} \wedge\left(\mathbf{V} \wedge \mathbf{F}_{\mathbf{d}}\right)\right|}
\end{aligned}
$$

$\mathbf{F}_{\mathbf{d}}$ : normal drag $(\mathrm{N})$ on $\mathbf{u}$ twines, following the assumptions of Landweber,

$\mathbf{T}_{\mathbf{d}}$ : tangential drag (N) on u twines, Richtmeyer hypothesis,

V: water velocity $(\mathrm{m} / \mathrm{s})$,

$\rho$ : density of water $\left(1025 \mathrm{~kg} / \mathrm{m}^{3}\right.$ in the present study),

$C_{d}$ : normal drag coefficient for a twine (1.2 in the present study),

$f:$ tangential drag coefficient (0.08 in the present study),

$D$ : diameter of twine (m),

$\alpha$ : angle between the $\mathbf{u}$ vector and the water velocity $\mathbf{V}$ (radians),

$n / 2$ : number of $\mathbf{u}$ twine vectors in the triangular element.

\subsection{Contact between knots}

It happens quite frequently that the nets are so close that the knots come into contact with each other. As a result this contact limits the closing of the mesh (Priour, 2013a). This contact is modeled as a couple $C$, which appears only when the twines are close enough, that is, when the angle between $\mathbf{u}$ and $\mathbf{v}$ twines $\alpha(\mathrm{rad})$ is below a critical angle $\alpha_{\min }(\mathrm{rad})$ :

$$
C=\left\{\begin{array}{cl}
H\left(\alpha-\alpha_{\text {min }}\right) & \text { if } \alpha \leq \alpha_{\text {min }} \\
0 & \text { if } \alpha>\alpha_{\text {min }}
\end{array}\right\}
$$

where $H$ is the stiffness $(\mathrm{Nm} / \mathrm{rad})$. The critical angle $\alpha_{\min }$ is evaluated according to the following expression: 
$\sin \left(\frac{\alpha_{\text {min }}}{2}\right)=\frac{\text { knot }_{\text {size }}}{\text { mesh }_{\text {side }}}$

The $k_{n o t}$ size is the size of the knot (m), and $m e s h_{\text {side }}$ is approximated as the unstretched length of the twine vector $l_{o}(\mathrm{~m})$.

\subsection{Bottom contact}

A contact with the bottom could lead to a vertical force $\left(F_{v}\right)$ and a friction force $\left(F_{h}\right)$ :

$$
\begin{aligned}
& F_{v}=B s e_{v} \\
& F_{h}=\text { Coef } F_{v}
\end{aligned}
$$

$F_{v}$ : vertical contact force on the bottom $(\mathrm{N})$,

$F_{h}$ : friction force on the bottom $(\mathrm{N})$,

Bs: bottom stiffness $(5000000 \mathrm{~N} / \mathrm{m}$ in the present study),

$e_{v}$ : penetration depth of node in the bottom $(\mathrm{m})$,

Coef: friction coefficient ( 1 in the present study, from Pashen 2000).

\subsection{Fish catch pressure}

The mechanical effect of a caught fish in a net is estimated as a pressure (Priour, 2013a). This pressure is exerted directly on the triangular elements in contact with the catch as follows:

$$
p=\frac{1}{2} \rho C_{d}|\mathbf{V}|^{2}
$$

$p$ : pressure of the catch on the net $(\mathrm{Pa})$,

$C_{d}$ : drag coefficient for the catch (1.4, from Priour 2013a).

This pressure is then applied on the surface of the triangular element $\left(\frac{\mathbf{S}_{12} \wedge \mathbf{S}_{13}}{2}\right)$ resulting in a total force directed perpendicularly to the triangular element. The effort on each vertex $\left(\mathbf{F}_{\mathbf{p} 1}\right.$, $\mathbf{F}_{\mathbf{p} 2}$ and $\mathbf{F}_{\mathbf{p} 3}$ ) is the total force divided by 3 .

$$
\mathbf{F}_{\mathbf{p} 1}=\mathbf{F}_{\mathbf{p} 2}=\mathbf{F}_{\mathbf{p} 3}=\frac{\mathbf{S}_{12} \wedge \mathbf{S}_{13}}{2} \frac{p}{3}
$$

\subsection{Door modelling}

Doors are modeled by a rectangle (visible in Figure 3). The forces on the doors are the weight (1400 kg), buoyancy (76 liter), and hydrodynamic forces (drag and lift). 


$$
\begin{aligned}
& F_{d}=\frac{1}{2} \rho C_{d} S|\mathbf{V}|^{2} \\
& F_{l}=\frac{1}{2} \rho C_{l} S|\mathbf{V}|^{2}
\end{aligned}
$$

with the following:

$C_{d}:$ drag coefficient for the doors (1.35),

$C_{l}:$ lift coefficient for the doors (1.43),

$S:$ surface of the door $\left(4.5 \mathrm{~m}^{2}\right)$,

The weight, surface, drag, and lift coefficients were provided by the door manufacturer.

\subsection{Catch volume model}

The FEM requires a knowledge of the netting surface area affected by the catch or, in other words, the netting in contact with the catch. From the catch mass, the catch volume is assessed assuming that the catch density is the same as the sea water, which could be acceptable as a first approximation. This volume of catch lines up the rearmost part of the netting and defines a limit to the catch (called front) on the netting, that is, all the catch is behind this front. In this study, this front is considered as a plane perpendicular to the towing direction. The volume inside the netting and behind the front includes the catch volume and also a volume of water. In the present work, the model developed by D. Priour and B. Herrmann is applied to assess the total volume inside the affected surface (Priour \& Herrmann, 2005).

The total volume inside the affected surface of netting, compounded by fish and water, is defined as $W B\left(\mathrm{~m}^{3}\right)$, and it depends on several parameters:

- $\quad P R$ : the catch volume in $\mathrm{m}^{3}$, it is the catch of fish in $\mathrm{kg}$ divided by the density of water $\left(1025 \mathrm{~kg} / \mathrm{m}^{3}\right)$.

- $P E$ : the stretched perimeter in $\mathrm{m}$. It is the mesh size multiplied by the number of meshes around.

- $\quad T A$ : the fish size in $\mathrm{m}^{3}$. It is the fish mass in $\mathrm{kg}$ divided by the density of water $(1025$

$\left.\mathrm{kg} / \mathrm{m}^{3}\right)$

- $\quad$ EI: the twine bending stiffness in $\mathrm{Nm}^{2}$.

- VI: The stop pressure of water in $\mathrm{N} / \mathrm{m}^{2}$. It is $1 / 2$ water density by square water speed.

From these dimensional parameters, 3 non-dimensional parameters have been defined:

- $\quad \frac{P R}{P E^{3}}$ characterises the size of the catch. 
- $\frac{T A}{P E^{3}}$ characterises the mean size of fish in the catch.

- $\frac{E I}{V I P E^{4}}$ is the ratio between the twine bending stiffness $(E I)$ and the pressure because of the flow $(V I)$.

From these 3 parameters, the total volume in the codend (catch and water) can be calculated using the following formula (Priour \& Herrmann, 2005):

$$
\frac{W B}{P R}=a\left(\frac{P R}{P E^{3}}\right)^{b}+c\left(\frac{T A}{P E^{3}}\right)^{d}+e\left(\frac{E I}{V I P E^{4}}\right)^{f}+g
$$

With

- $a=1.785$

- $\quad b=-0.0548$

- $\quad c=-1.652 \mathrm{E}+10$

- $d=1.919$

- $e=4.406 \mathrm{E}-3$

- $f=-0.172$

- $g=-0.0157$

\subsection{Sum of the forces}

To date, the forces applied to each triangular element and bar element are calculated. These forces are spread on each node (vertices of each triangle and extremities of bars for cables and chains). The force components of all triangles and bars are added to obtain the entire forces applied to each node. The complete loading is the sum of forces, which depends on tension, drag, buoyancy, weight, twine contact, and catch:

$$
\mathbf{F}=\mathbf{F}_{\mathrm{e}}+\mathbf{F}_{\mathrm{d}}+\mathbf{F}_{\mathrm{f}}+\mathbf{F}_{\mathrm{w}}+\mathbf{F}_{\mathrm{t}}+\mathbf{F}_{\mathrm{c}}+\mathbf{F}_{\mathrm{o}}+\mathbf{F}_{\mathrm{b}}
$$

where $\mathbf{F}$ is the total loading on net and bars, defined as the sum of all the forces described previously, which are as follows: $\mathbf{F}_{\mathbf{e}}$ due to the twine and cable tension, $\mathbf{F}_{\mathbf{d}}$ is the drag force on twines and bars, $\mathbf{F}_{\mathbf{c}}$ is related to the pressure of the catch, $\mathbf{F}_{\mathbf{t}}$ includes the knot contact, $\mathbf{F}_{\mathbf{o}}$ is the force applied on the doors, $\mathbf{F}_{\mathbf{b}}$ is the bottom contact, and $\mathbf{F}_{\mathbf{f}}$ and $\mathbf{F}_{\mathbf{w}}$ are due to the buoyancy and the weight of net and bars, respectively.

\subsection{Method of numerical calculation}

Forces $(\mathbf{F})$ are calculated on each node. These forces depend on the nodes position (X). Thus, the relation $\mathbf{F}(\mathbf{X})$ is established. Obviously, in most of the net shape calculations, the initial 
position $\left(\mathbf{X}_{\text {initial }}\right)$ of the nodes, arbitrarily defined by the user of the FEM model, is not at equilibrium, so $\mathbf{F}\left(\mathbf{X}_{\text {initial }}\right) \neq \mathbf{0}$. To achieve the equilibrium position $\left(\mathbf{X}_{\text {final }}\right)$, where $\mathbf{F}\left(\mathbf{X}_{\text {final }}\right)=\mathbf{0}$, the Newton-Raphson iterative method is used:

$$
\mathbf{X}_{\mathrm{k}+1}=\mathbf{X}_{\mathrm{k}}+\frac{\mathbf{F}\left(\mathbf{X}_{\mathrm{k}}\right)}{-\mathbf{F}^{\prime}\left(\mathbf{X}_{\mathrm{k}}\right)}
$$

where $\mathbf{X}_{\mathbf{k}+\mathbf{1}}$ is the nodes position (m) vector at iteration $k+1, \mathbf{F}\left(\mathbf{X}_{\mathbf{k}}\right)$ is the force vector $(\mathrm{N})$ on nodes at iteration $k$, and $-\mathbf{F}^{\prime}\left(\mathbf{X}_{\mathbf{k}}\right)$ is the matrix of opposite derivatives of force (also called stiffness matrix) on nodes at iteration $k(\mathrm{~N} / \mathrm{m})$.

A large displacement of the structure (net and cable) can be obtained by this usual method. It consists in applying total force $(\mathbf{F}(\mathbf{X}))$ and stiffness $\left(-\mathbf{F}^{\prime}(\mathbf{X})\right)$ to revise the coordinates $(\mathbf{X})$ of nodes. At every stage, total force and stiffness depend on the new position of the nodes. The process is repeated until the total force is very small.

\section{Results}

\subsection{Values of recorded parameters}

Table 1 gives the mean and standard deviation of all parameters recorded on the trawl and on board during the 37 hauls. It is noticeable that the standard deviation of the ground speed is much larger than the standard deviation of the water speed.

\subsection{Haul duration effect}

The door spread displayed in Figure 6 was measured at sea. For most hauls, it appears quite clearly that the door spread decreases with time since the beginning of the haul if the former and later minutes are neglected, as can be seen in Figure 6. The linear relation between door spread and time since the beginning of the haul is calculated for each haul. In Figure 6, this relation is

$D S=69.1-1.28 H T$

$D S=$ door spread $(\mathrm{m})$,

$H T=$ time since the beginning of the haul (h).

This means that the door spread at the beginning of the haul is estimated to be $69.1 \mathrm{~m}$, and the decrease of the spread is assessed to be $1.28 \mathrm{~m}$ per hour.

For each haul a linear regression has been calculated, resulting in 37 relations given by 37 pairs of linear regression coefficients. The mean and the standard deviation of all of them give the relation:

$D S=58.5( \pm 7.35)-1.35( \pm 1.98) H T$

This means that the mean spread at the beginning of the hauls is $58.5 \mathrm{~m}$, and the mean decrease is $1.35 \mathrm{~m} / \mathrm{h}$. This also means that for a few hauls the spread increases, which could be due to speed variation and to a small catch volume. 
In Figure 7, all the hauls are displayed, the first 5 minutes and the last 2 minutes of each haul have been removed from Figure 7 and from the calculation of the regressions. In Figure 7, at every time, the linear relations of the hauls are used to estimate 37 values of the door spread, from which a mean and a standard deviation are obtained. The central line is the mean and the two curves below and above are the mean values adding or subtracting the standard deviation.

\subsection{Effect of the catch on the door spread and on the top and bottom tensions.}

To explain the decrease in the spread with haul time, the catch in the trawl has been simulated in the model. The authors define 3 durations since the beginning of the haul: $0 \mathrm{~h}, 1.5 \mathrm{~h}$, and 3 $\mathrm{h}$. According to the hypothesis that the catch increases linearly with time, $0 \mathrm{~h}$ obviously represents the empty codend; at $1.5 \mathrm{~h}$, the codend is suspected half full $(0.74 \mathrm{ton})$, and at $3 \mathrm{~h}$, the codend is suspected full (1.48 tons).

As described in Section 4.8, the model requires the catch volume $W B$. This volume $W B$ depends on different parameters: the perimeter $P E(\mathrm{~m})$, the catch volume $P R\left(\mathrm{~m}^{3}\right)$, the fish size $T A\left(\mathrm{~m}^{3}\right)$, the twine bending stiffness $E I\left(\mathrm{Nm}^{2}\right)$, and the stop pressure $V I\left(\mathrm{~N} / \mathrm{m}^{2}\right)$. These parameters are quantified during the fishing performance, but unfortunately, there is a degree of uncertainty in their estimation, which could be high in some cases. To overcome this, an interval of possible values for $W B$ is calculated.

After discussion with the fishermen, it was concluded that the perimeter of the codend $(P E)$ is accurate at $1 \%$, which means that for a mean perimeter of $12 \mathrm{~m}$, the minimal value is $11.88 \mathrm{~m}$, and the maximal one is $12.12 \mathrm{~m}$. Moreover, it concludes that the catch could vary by $10 \%$, and the fish volume could vary from 0.1 to 11 and up to 101 . Measurements at sea show that water speed is $1.60 \pm 0.12 \mathrm{~m} / \mathrm{s}$ (Table 1). From previous work (Priour \& Herrmann, 2005), the twine bending stiffness $E I$ for this netting could vary from 0.001256 to $0.002513 \mathrm{Nm}^{2}$ and up to $0.005026 \mathrm{Nm}^{2}$. Table 2 shows the mean, maximum and minimum values for the different characteristics of the fishing process (perimeter of the codend, mass of the catch, size of the fish, water speed, and the twine bending stiffness $E I$ ), which are used to evaluate the parameters $P E, P R, T A$, and $V I$, respectively. The justification of these values is also included in Table 2.

These values can be combined in different ways to evaluate the catch volume (Equation 28), resulting in 243 possibilities ( 3 cases for 5 parameters). From these 243 possibilities, we have selected the minimum, the maximum and a third value called the mean. The mean is in fact the value obtained by the mean of the 5 parameters. Table 3 displays $W B$ and its respective parameters for the half catch stage and the full catch stage.

The variation in parameters also affects the conditions for the simulation, particularly, in the case of the water speed, which is $1.48,1.6$, and $1.72 \mathrm{~m} / \mathrm{s}$ for the minimum, mean, and maximum values for $W B$, as shown in Table 3. The twine bending stiffness EI may also influence the net shape, but it is not included in the numerical model because from our experience the effect is very low. EI is just used in the calculation of $W B$.

Consequently, a simulation has been made for each of the 9 load stages: empty-max, emptymean, empty-min, half-max, half-mean, half-min, full-max, full-mean, and full-min, as indicated in Table 4. The results in terms of door spread and bridle tension are also reported in Table 4. The trawl shapes are displayed in Figure 8 for the mean values. These simulation 
results are displayed in Figure 7 for the door spread, Figure 9 for the bottom tension, and Figure 10 for the top tension.

\section{Discussion and conclusion}

The fitting of the simulations with the measurements is reasonably good for the door spread (Figure 7), the bottom tension (Figure 9), and the top tension (Figure 10). This means that the variation in shape during the haul duration is probably mostly due to the catch increase:

- In Figure 7, the door spread vs the duration (or the catch) is represented for the experimental data and the simulation results. The simulation results are within the interval defined by the standard deviation of the data. Measurements and the numerical model have a similar decrease as the catch increases: the mean slope for the measurements is $-1.35 \mathrm{~m} / \mathrm{h}( \pm 1.98$ $\mathrm{m} / \mathrm{h}$ ), and that of the numerical calculations is $-1.06 \mathrm{~m} / \mathrm{h}$. Moreover, the effect of water speed and catch volume are coupled, and both influence the door spread. However, despite the influence of the water speed, there is a clear effect of the catch as a general decrease in the value of the door spread for $0,1.5$, and $3 \mathrm{~h}$.

- For the bottom tension (Figure 9), the measurements and the simulation show approximately no variation in the catch and quite similar values; it could be concluded that the catch has no effect. The mean slope for the experimental data is $+5.27 \mathrm{~kg} / \mathrm{h}( \pm 54 \mathrm{~kg} / \mathrm{h})$, and that of the simulation is $-8.29 \mathrm{~kg} / \mathrm{h}$, which is within the range defined by the standard deviation of the data.

- The top tension data (Figure 10) seem much more sensitive to the influence of the catch, and the simulation results, which are quite close to the mean values of the measurements. The measurements present an increment of $47.30 \mathrm{~kg} / \mathrm{h}( \pm 59.40 \mathrm{~kg} / \mathrm{h})$, and the numerical results show a slope of $76.01 \mathrm{~kg} / \mathrm{h}$.

The other parameters measured at sea do not seem to be affected by the catch, such as the vertical opening or the warp tension.

As shown previously, although the experiments and simulation seem quite similar, they do present some differences. These differences may be due to some factors:

-The modeling uses a uniform speed around the trawl, up to the catch. This hypothesis is probably debatable: the hydrodynamic drag of the netting leads necessarily to a decrease in water speed. While this decrease is not known and because this decrease is suspected to be quite small, the model uses an acceptable hypothesis.

-In this study, a catch has been assessed identical for all the hauls. For future work on this subject, it would be beneficial to record the catch after each haul in order to model each haul with more accurate conditions.

-The twine bending stiffness has not been included in the numerical model, and it has been demonstrated that it could have a clear influence on the final shape of the net (Priour, 2013a). The incorporation of this effect in the numerical model could also reduce the difference between the experimental and numerical results. 
-Another hypothesis worthy of improvement is that the hydrodynamic forces on the doors (drag and lift) remain constant with the water speed as they have been calculated with the mean value of the water speed, that is, $1.60 \mathrm{~m} / \mathrm{s}$.

-As stated in Section 3.2, a method to cancel some hauls or recordings which were not of sufficient quality has been determined and used. The quality of this method of cancellation could be verified, for example, by changing the limits of cancellation by $10 \%$ or $20 \%$ and checking that it does not change the demonstration of this paper.

-In this study, the modeling has been done for a trawl in mean conditions with more or less variation on a few parameters (perimeter, catch, fish size, water speed, and twine bending stiffness). There would probably be an improvement if the modeling was carried out for each haul, for example, in the case of Figure 6, the modeling could model the exact conditions of this haul. These precise conditions include the depth and water speed, which were recorded during this haul.

-The relation between the catch mass and volume $(W B)$ inside the netting affected by the catch is based on two points: the density of the catch is the same as the density of sea water, and the ratio of the volume inside the netting behind the front on the catch volume is extracted from flume tank tests. It is quite clear that the density of fish is not exactly the density of water, and this difference could slightly affect the volume of the catch. It is also clear that the ratio of the volume behind the front on the catch volume could influence significantly the netting surface area affected by the catch. It would be of interest to measure such relation at sea, for example, by underwater video.

\section{Acknowledgements}

The author wishes to thank the Wacogne family, the crew of the boat "Arc-en-ciel," the French ministry of Fisheries, and the European funds for fisheries that contributed to this study.

\section{References}

- Ferro R.S.T., van Marlen B., Hansen K.E., 1996, An empirical velocity scale relation for modelling a design of large mesh pelagic trawl, Fisheries Research, Volume 28, Issue 2, September 1996, Pages 197-230.

- Lee, C.-W., Lee J.-H., Cha B.-J., Kim H.-Y., Lee, J.-H., 2005, Physical modeling for underwater flexible systems dynamic simulation, Ocean Engineering, Volume 32, Issues 3-4, Pages 331-347.

- O’Neill, F.G., Knudsen, L.H., Wileman, D.A., McKay, S.J, 2005. Codend drag as a function of catch size and towing speed, Fisheries Research, Volume 72 , Pages 163-171.

- Park, H.H., 2007, A method for estimating the gear shape of a mid-water trawl, Ocean Engineering, Volume 34 (2007), Pages 470-478.

- Pashen M., Richter U., Köpnick W., 2000, Trapese Trawl Penetration in the Seabed, Final report, Contract No. 96-006, Rostock, 2000-4, Research project of European Community, Directorate General XIV-Fisheries. 
- Priour, D., 1999. Calculation of net shapes by the finite element method with triangular elements. Communications in Numerical Methods in Engineering, Volume 15, Issue 10, Pages 755-763.

- Priour, D., 2003. Analysis of nets with hexagonal mesh using triangular elements, International Journal for Numerical Methods in Engineering, Volume 56, Issue 12, 28, Pages 1721-1733.

- Priour D. \& Herrmann B., 2005, Catch shape in codend, Proceedings of the seventh International Workshop on Methods for the development and Evaluation of Marine Technologies, Busan 23-26 November 2005, Pages 41-57.

- Priour, D., O’Neill, F., Sala, A., Chevallier, P., Hermann, B., 2006. PREMECS-II: Development of predictive model of codend selectivity, Final Report, Contract n० Q5RS2002-01328.

- Priour, D., 2012. Rapport final du projet EFFICHALUT , 01 - 2012 - Rapport DCB/RDT/HO/R12-001.

- Priour, D., 2013a. A finite element method for netting. Application to fish cages and fishing gear. ISBN 978-94-007-6843-7. Springer Briefs in Environmental Science. Springer.

- Priour, D., 2013b. The effect of catch weight on trawl behaviour, Proceedings of DEMAT 2013 Conference, Contributions on the theory of fishing gears and related marine systems. Vol. 8, Rostok, October 2013, Pages 3-12.

- Sala, A., De Carlo, F.,Buglioni, G., Lucchetti, A., 2011, Energy performance evaluation of fishing vessels by fuel mass flow measuring system, Ocean Engineering, Volume 38, Issues 5-6, April 2011, Pages 804-809.

- Tsukrov, I., Eroshkin, O. Fredriksson, D. Swift M.R. and Celikkol B., 2003. Finite element modeling of net panels using a consistent net element, Ocean Engineering Volume 30, Issue 2, February 2003, Pages 251-270.

- Ward J.N., Ferro R.S.T., 1993, A comparison of one-tenth and full-scale measurements of the drag and geometry of a pelagic trawl, Fisheries Research, Volume 17, Issues 3-4, August 1993, Pages 311-331. 


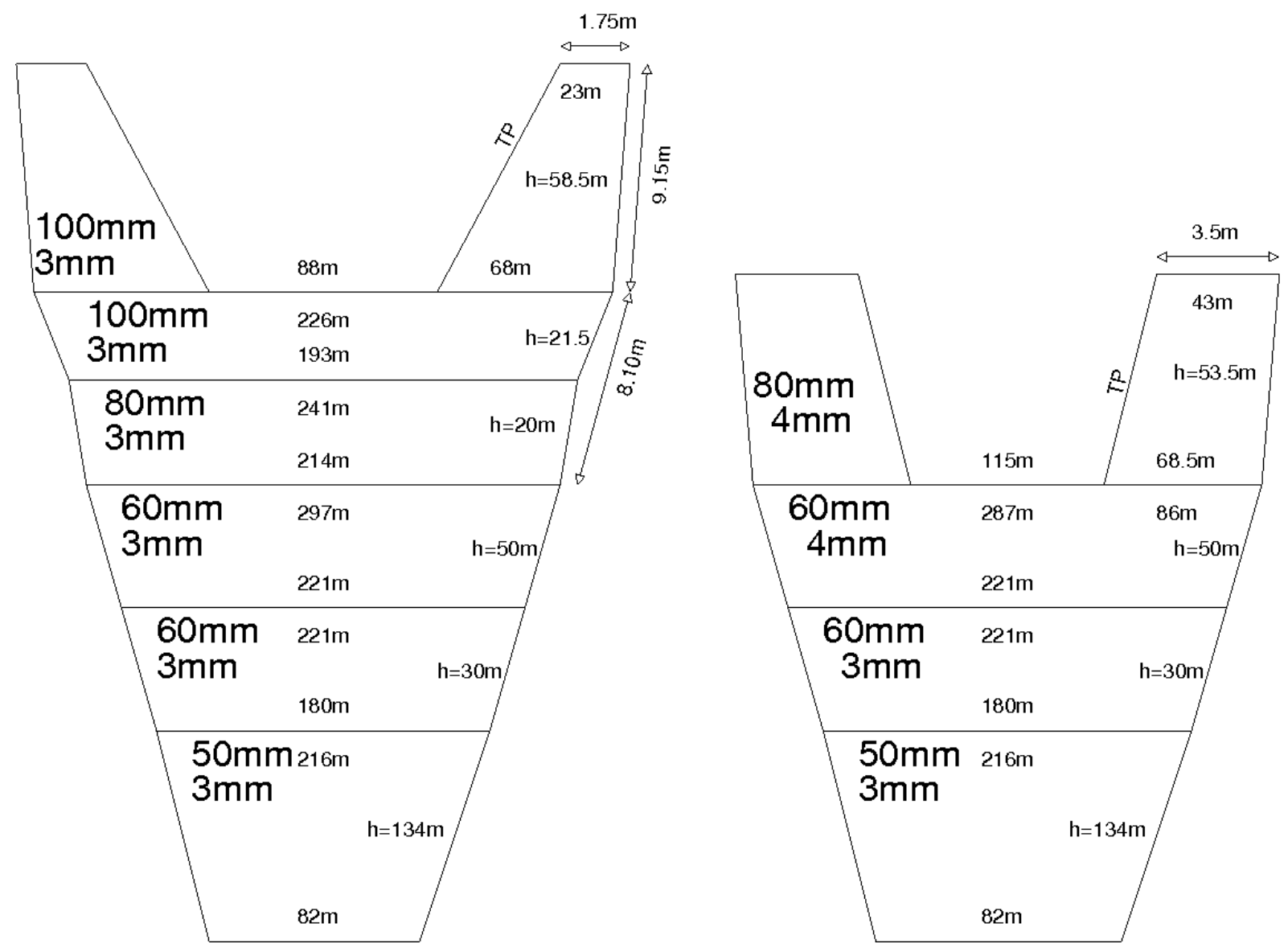

Figure 1 : Design of the trawl. The mesh size and twine diameter are on the left. The panels size is noted in mesh numbers and the cables in meters.

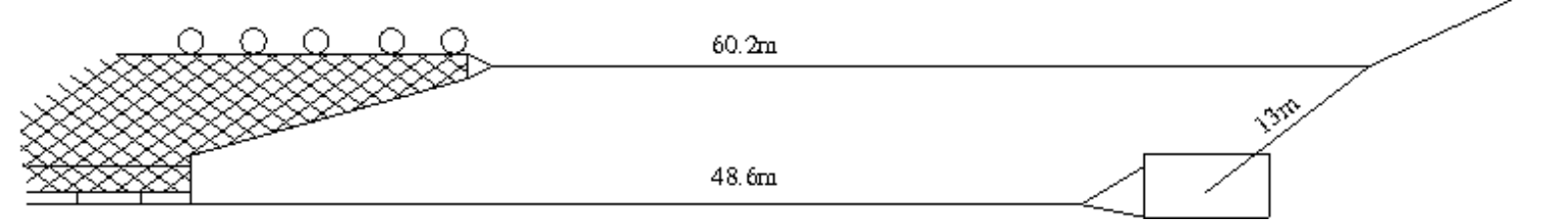

Figure 2: Design of the rigging. The top bridle is fixed to the warp. 


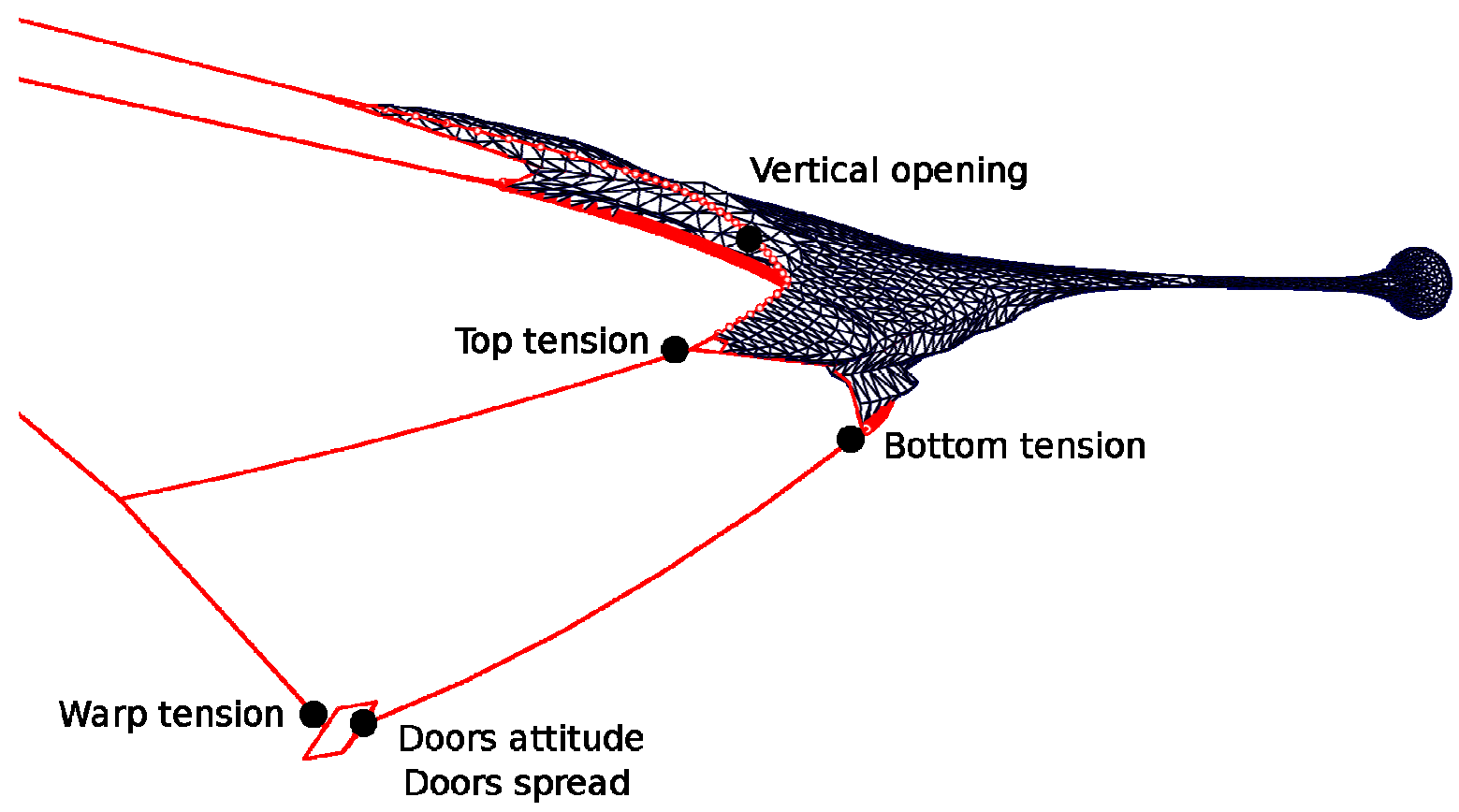

Figure 3 : View of the simulated trawl. a) The net is split into contiguous triangles in the modelling. The door is between the warp and the bottom bridle. b) Position of the port sensors on the trawl. 6 Tension sensors are placed on the warp, bottom and top bridles, port and starboard. The door attitude sensor measures the depth, the heel and the trim, port and starboard. The door spread and the vertical opening of the trawl are measured. 


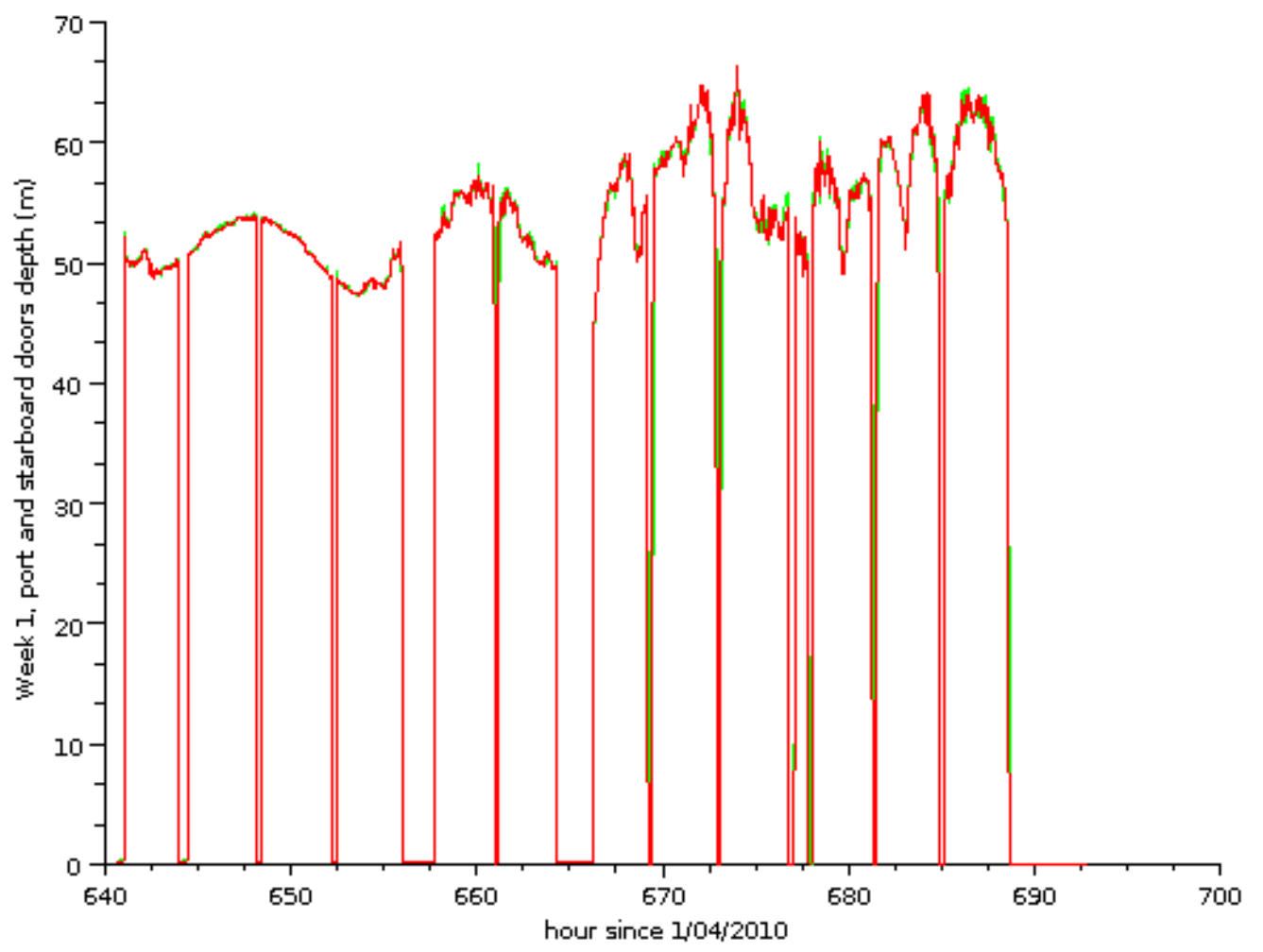

Figure 4: Depth of port and starboard doors during the first hauls. The beginning and the end of the 12 hauls are easily determined (when the depth passes $10 \mathrm{~m}$ ). Hauls with a duration of less than $1.5 \mathrm{~h}$ are not taken into account in the study (such as the haul at $677 \mathrm{~h}$ ). 


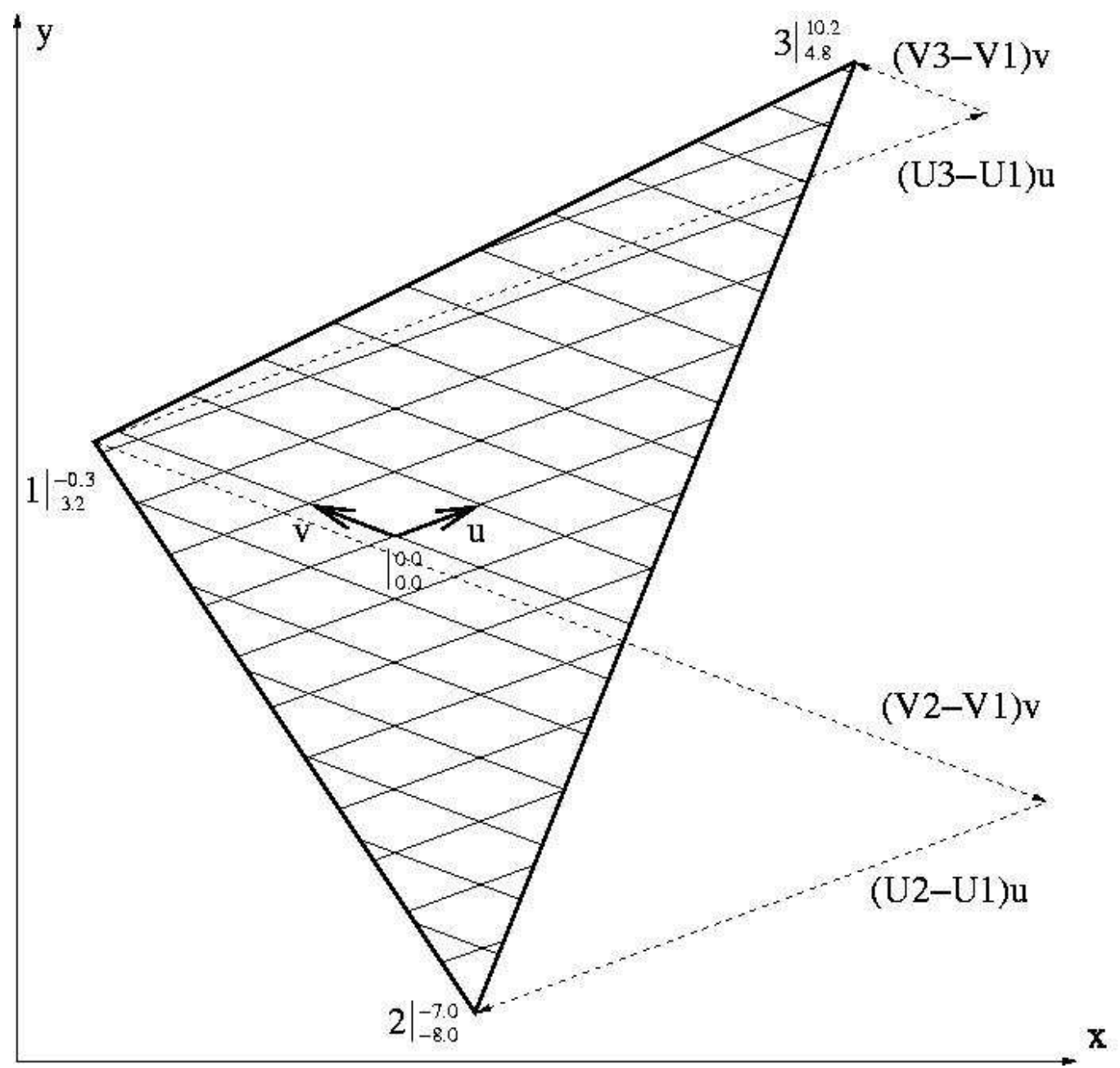

Figure 5: Triangular element used in the modelling for nets with two twine directions $(\mathbf{u}, \mathbf{v})$. The vertices are 1,2 and 3. The co-ordinates in mesh numbers are marked. The triangle sides are linear combinations of twine vectors $(\mathbf{u}$ and $\mathbf{v})$. 


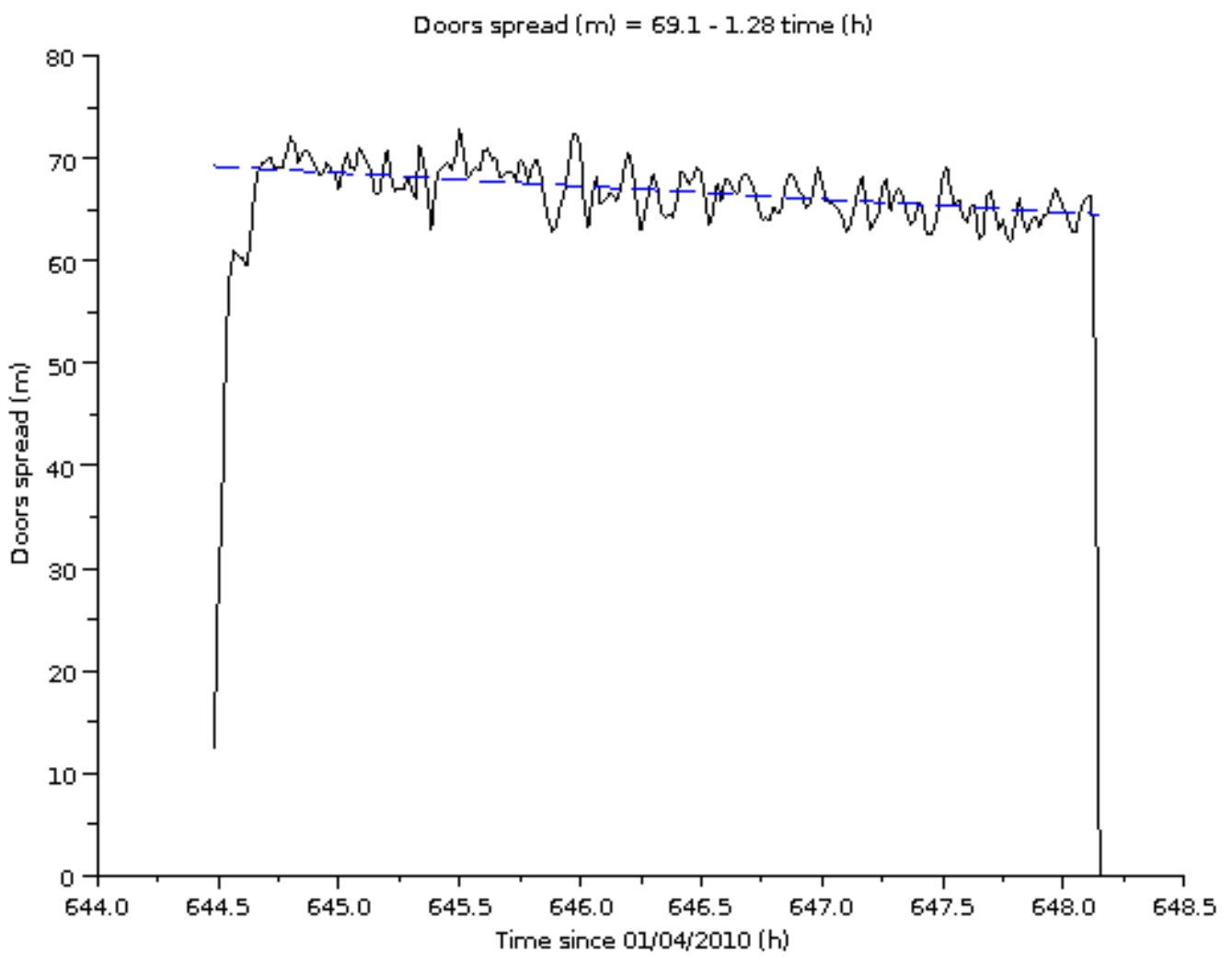

Figure 6: Door spread for the first haul. Except for the first and last minutes, there is a decrease of around $5 \mathrm{~m}$ between the beginning and the end of the haul. The linear relation between the door spread and the time since the beginning of the haul shows that the spread decreases by $1.28 \mathrm{~m} / \mathrm{h}$. The drag on the catch is suspected in this decrease. 


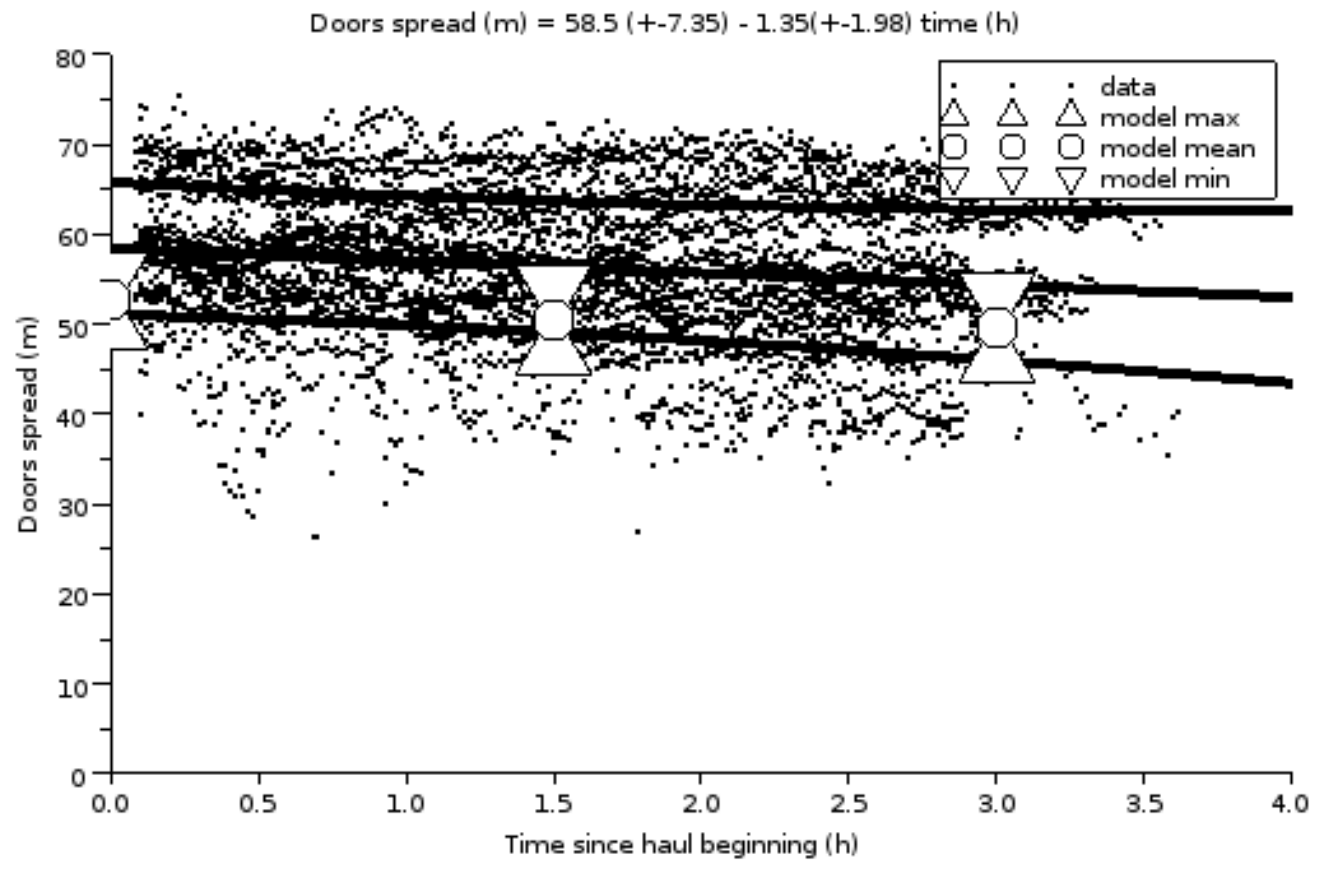

Figure 7: Door spread versus time since the beginning of haul for every haul. The line is the mean value of the spread and the two curves above and below the line are mean values plus and minus the standard deviation, see the text for explanation. The modelling of an empty trawl $(0 \mathrm{~h})$, half mean catch $(1.5 \mathrm{~h})$ and full mean catch $(3 \mathrm{~h})$ are noted. To take into account uncertainties, the mean, maximum and minimum values of the catch volume are modeled. Measurements and simulations are quite similar and show a decrease in the spread due to the catch. 


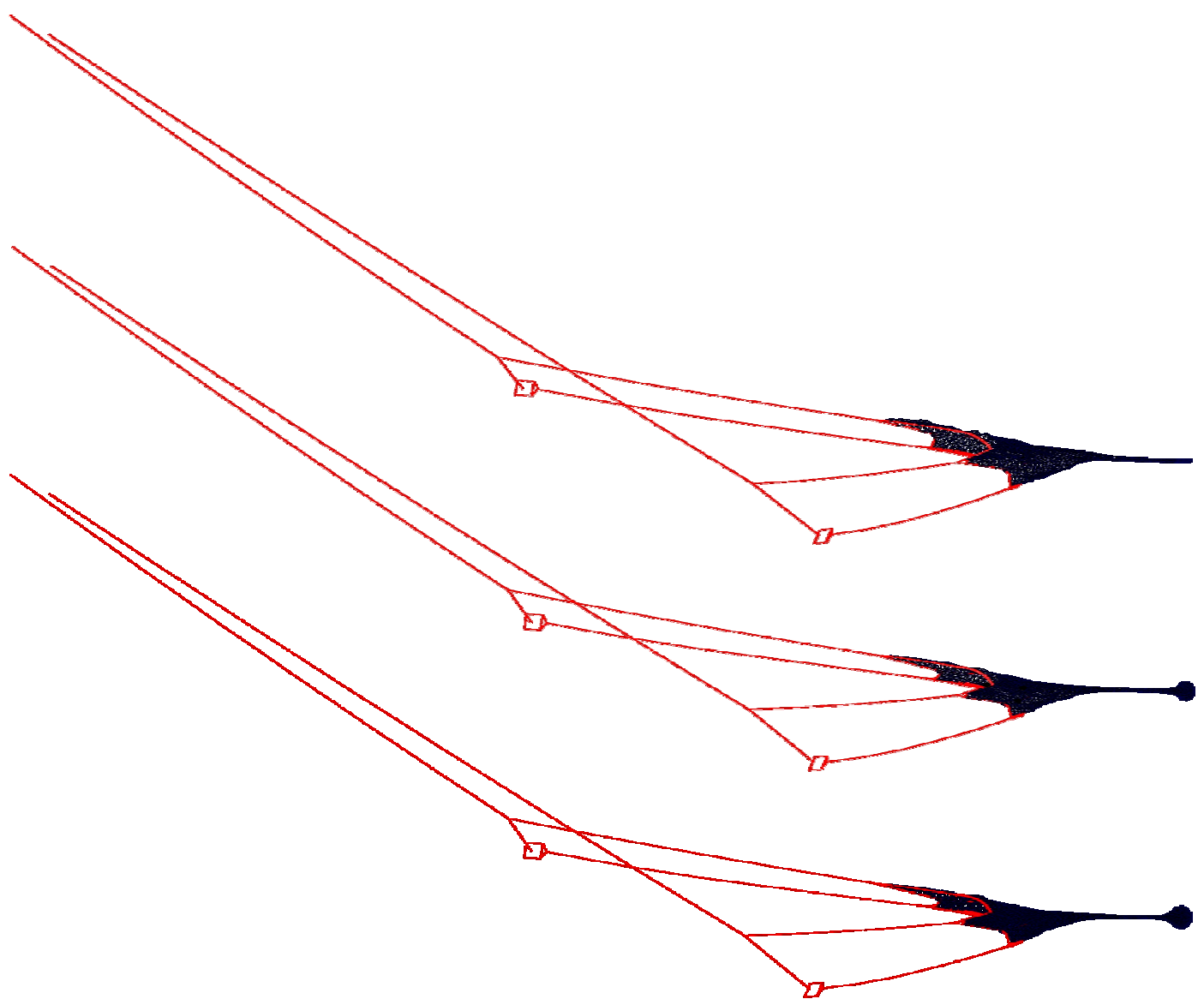

Figure 8: Simulation of empty trawl (top), half mean catch (middle) and full mean catch (bottom). It is noticeable that the catch increases. 


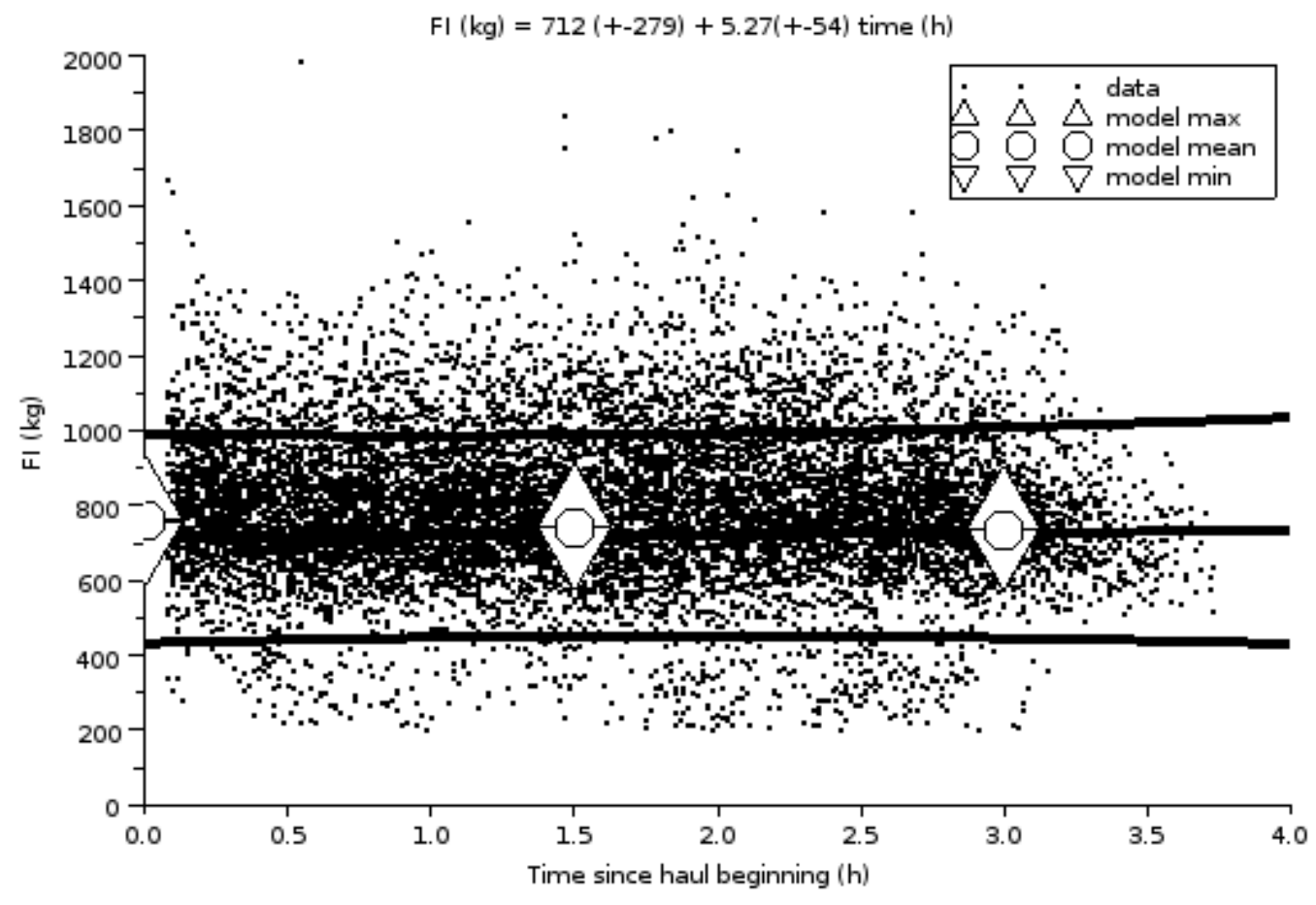

Figure 9: Bottom bridle tension versus time since the beginning of the haul for every haul (same comments as figure 7). Measurements and simulations are similar and show virtually no variation in bottom tension due to the catch. 


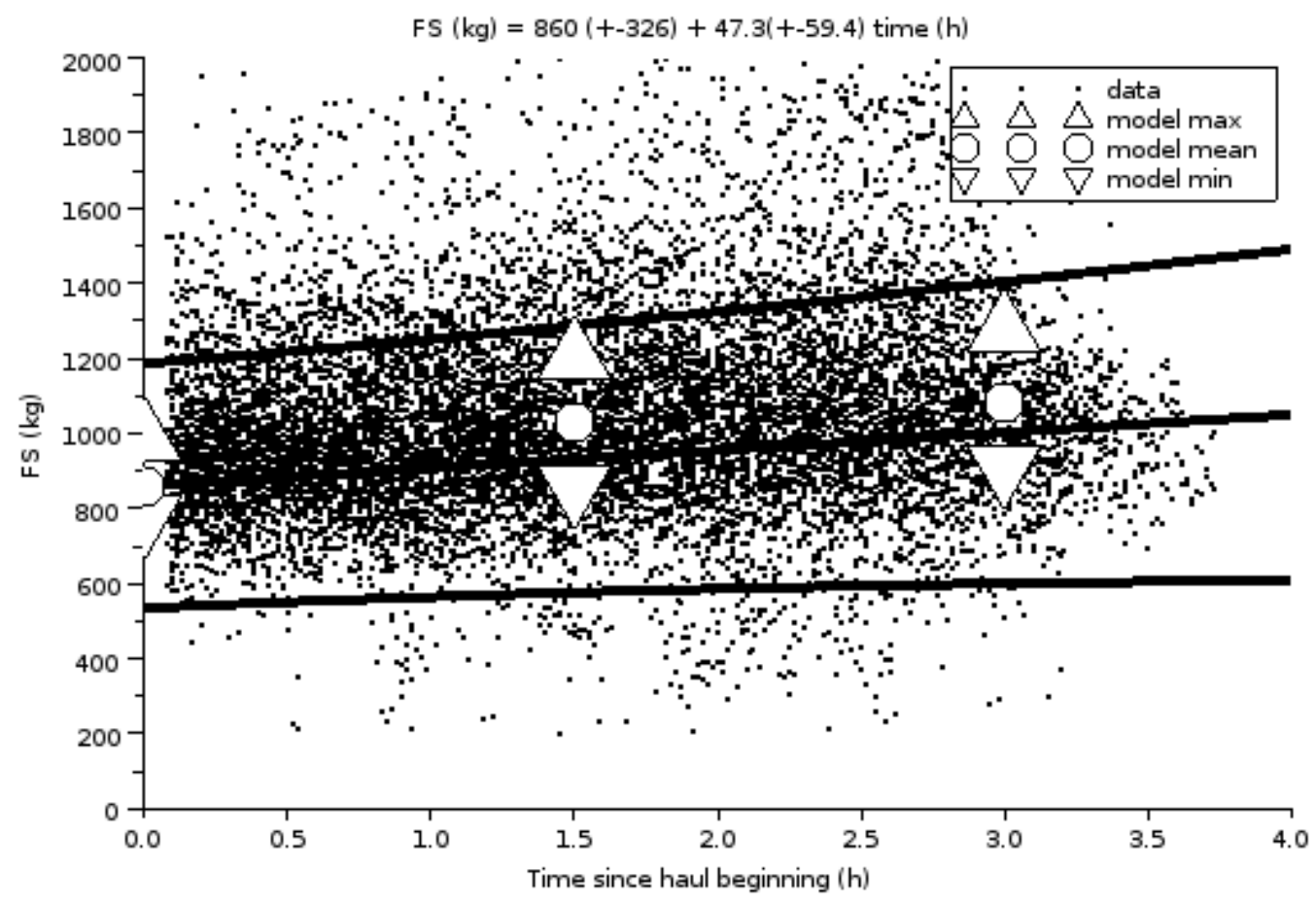

Figure 10: Top bridle tension versus time since the beginning of the haul for every haul (same comments as figure 7). Measurements and simulations are similar and show an increase in top tension due to the catch. 


\begin{tabular}{|l|l|l|}
\hline & mean & Standard deviation \\
\hline Bottom bridle tension $(\mathrm{Kg})$ & 798 & 198 \\
\hline Top bridle tension $(\mathrm{Kg})$ & 1040 & 257 \\
\hline Warp tension $(\mathrm{Kg})$ & 2244 & 588 \\
\hline Depth $(\mathrm{m})$ & 30 & 19 \\
\hline Doors pitch $\left(^{\circ}\right)$ & 1.8 & 11 \\
\hline Doors roll $\left(^{\circ}\right)$ & 1.6 & 23 \\
\hline Door spread $(\mathrm{m})$ & 58 & 7.8 \\
\hline Ground speed $(\mathrm{m} / \mathrm{s})$ & 1.53 & 0.43 \\
\hline Water speed $(\mathrm{m} / \mathrm{s})$ & 1.60 & 0.12 \\
\hline Vertical opening $(\mathrm{m})$ & 4.2 & 0.62 \\
\hline Haul duration $(\mathrm{min})$ & 185 & 24 \\
\hline
\end{tabular}

Table 1: Mean and standard deviation of recorded parameters during the 37 hauls. 


\begin{tabular}{|l|l|l|l|l|l|}
\hline & Codend Perimeter & Catch Mass & Fish Size & Water Speed & EI \\
\hline Max & $(\mathrm{m})$ & (tons $)$ & $\left(\mathrm{m}^{3}\right)$ & $(\mathrm{m} / \mathrm{s})$ & $\left(\mathrm{Nm}^{2}\right)$ \\
\hline Mean & 12.12 & 1.63 & 0.01 & 1.72 & 0.005026 \\
\hline Min & 11.88 & 1.48 & 0.001 & 1.60 & 0.002513 \\
\hline Justification & $\begin{array}{l}\text { Fishermen } \\
\text { experience }\end{array}$ & $\begin{array}{l}\text { Fishermen } \\
\text { experience }\end{array}$ & $\begin{array}{l}\text { Fishermen } \\
\text { experience }\end{array}$ & Measurements & $\begin{array}{l}(\text { Priour, } \\
2005)\end{array}$ \\
\hline
\end{tabular}

Table 2: Maximum, mean and minimum values used for the codend perimeter, the mass of the catch, the fish size, the water speed and the flexural rigidity. These values are used to evaluate the parameters $P E, P R, T A, V I$ and $E I$, respectively, according to the formulation described in Section 4.8. Moreover, the choice of these values are justified by the observations of the fishermen, the measurements during the fishing process and the bibliography. 


\begin{tabular}{|l|l|l|l|l|l|l|l|}
\hline & Duration & $P E$ & $P R$ & $T A$ & $V I$ & $E I$ & Vol.(WB) \\
\hline Empty & 0 & $(\mathrm{~h})$ & $\left(\mathrm{m}^{3}\right)$ & $\left(\mathrm{m}^{3}\right)$ & $\left(\mathrm{N} / \mathrm{m}^{2}\right)$ & $\left(\mathrm{Nm}^{2}\right)$ & $\left(\mathrm{m}^{3}\right)$ \\
\hline Half-max. & 1.5 & 12.12 & 0.79 & 0.0001 & 1516.18 & 0.001257 & $\mathbf{2 . 3 7}$ \\
\hline Half-mean & 1.5 & 12.00 & 0.72 & 0.001 & 1312.00 & 0.002513 & $\mathbf{2 . 1 2}$ \\
\hline Half-min. & 1.5 & 11.88 & 0.65 & 0.01 & 1122.57 & 0.005026 & $\mathbf{0 . 8 9}$ \\
\hline Full-max. & 3 & 12.12 & 1.59 & 0.0001 & 1516.18 & 0.001257 & $\mathbf{4 . 5 8}$ \\
\hline Full-mean & $\mathbf{3}$ & 12.00 & 1.45 & 0.001 & 1312.00 & 0.002513 & $\mathbf{4 . 0 9}$ \\
\hline Full-min. & 3 & 11.88 & 1.30 & 0.01 & 1122.57 & 0.005026 & $\mathbf{1 . 6 5}$ \\
\hline
\end{tabular}

Table 3: Catch volume $W B$ at $0 \mathrm{~h}, 1.5 \mathrm{~h}, 3 \mathrm{~h}$. Mean, maximal and minimal values are noted. This defines the following load stages: empty, half-max, half-mean, half-min, full-max, fullmean and full-min. The duration and the values of the parameters $P E, P R, T A, V I$ and $E I$ are also indicated.*NR: Not Relevant. 


\begin{tabular}{|l|l|l|l|l|l|l|}
\hline & Dur. & Vol. $(W B)$ & Water speed & Door Spread & Bottom Tension & Top Tension \\
\hline & $(\mathrm{h})$ & $\left(\mathrm{m}^{3}\right)$ & $(\mathrm{m} / \mathrm{s})$ & $(\mathrm{m})$ & $(\mathrm{kg})$ & $(\mathrm{kg})$ \\
\hline Empty-max. & 0 & 0 & 1.72 & 49.56 & 820.80 & 981.24 \\
\hline Empty-mean & $\mathbf{0}$ & $\mathbf{0}$ & $\mathbf{1 . 6 0}$ & $\mathbf{5 2 . 7 8}$ & $\mathbf{7 6 0 . 1 4}$ & $\mathbf{8 5 7 . 3 9}$ \\
\hline Empty-min. & 0 & 0 & 1.48 & 55.60 & 703.16 & 778.80 \\
\hline Half-max. & 1.5 & 2.37 & 1.72 & 46.82 & 795.62 & 1203.26 \\
\hline Half-mean & $\mathbf{1 . 5}$ & $\mathbf{2 . 1 2}$ & $\mathbf{1 . 6 0}$ & $\mathbf{5 0 . 3 8}$ & $\mathbf{7 3 6 . 8 0}$ & $\mathbf{1 0 3 2 . 2 1}$ \\
\hline Half-min. & 1.5 & 0.89 & 1.48 & 54.32 & 685.32 & 859.12 \\
\hline Full-max. & 3 & 4.58 & 1.72 & 46.06 & 791.74 & 1271.05 \\
\hline Full-mean & $\mathbf{3}$ & $\mathbf{4 . 0 9}$ & $\mathbf{1 . 6 0}$ & $\mathbf{4 9 . 6 0}$ & $\mathbf{7 3 5 . 2 7}$ & $\mathbf{1 0 8 5 . 4 2}$ \\
\hline Full-min. & 3 & 1.65 & 1.48 & 53.38 & 683.89 & 912.54 \\
\hline
\end{tabular}

Table 4: Results of the simulation for the 9 load stages (empty-max, empty-mean, emptymin, half-max, half-mean, half-min, full-max, full-mean and full-min). The duration (Dur.), the water speed, the catch volume $W B$ (calculated previously in Table 4) are also indicated. The door spread, bottom tension and top tension are provided by the calculation with FEM. It can be observed that, as the catch volume increases, the spread decreases when the bottom tension is more or less constant and the top tension increases. These values of door spread (bottom and top tension) are plotted in figure 7 ( 9 and 10). 